Funding: This study was funded by the Medical Research Council, with funding allocated from the health departments under the aegis of the Medical Research Council and UK health departments Sexual Health and HIV Research Strategy Committee.

Competing interests: None declared.

Ethical approval: Scientific and Ethical Advisory Group of the general practice research database.

1 Health Protection Agency. Focus on prevention. HIV and other sexually transmitted infections in the United Kingdom in 2003. Annual report. London: HPA, Nov 2004
2 Department of Health. The national strategy for sexual health and HIV. London: DoH, 2001.

3 Fenton KA, Korovessis C, Johnson AM, McCadden A, McManus S, Wellings K, et al. Sexual behaviour in Britain: reported sexually transmitted infections and prevalent genital Chlamydia trachomatis infection. Lance 2001;358:1851-4.

4 Majeed A. Sources, uses, strengths and limitations of data collected in primary care in England. Health Stat Q 2004;(21):5-14.

PHLS, DHSS\&PS, and Scottish ISD(D)5 Collaborative Group. Trends in sexually transmitted infections in the United Kingdom 1990-1999. London: Public Health Laboratory Service, 2000.

\title{
Timing of mortality among internally displaced persons due to the tsunami in Sri Lanka: cross sectional household survey
}

Nobuyuki Nishikiori, Tomoko Abe, Dehiwala G M Costa, Samath D Dharmaratne, Osamu Kunii, Kazuhiko Moji

Research Center for Tropical Infectious Diseases, Institute of Tropical Medicine, Nagasaki University, 1-12-4 Sakamoto,

Nagasaki 852-8523, Japan

Nobuyuki Nishikiori assistant professor

Tomoko Abe PhD student

Osamu Kunii professor

Kazuhiko Moji professor

Department of Community

Medicine, Faculty of

Medicine,

University of

Peradeniya, Kandy,

Sri Lanka

Dehiwala G M

Costa

Postgraduate Institute

of Medicine trainee

Samath D

Dharmaratne

senior lecturer

Correspondence to:

N Nishikiori

nobu@net.nagasaki-u.

ac.jp

BMJ 2006;332:334-5

\section{Abstract}

Objective To describe the distribution of mortality among internally displaced persons during two and a half months after the Indian Ocean tsunami, 2004. Design Cross sectional household survey with retrospective cohort analysis of mortality.

Setting Camps for internally displaced persons due to the tsunami in an eastern coastal district of Sri Lanka. Participants 3533 people from 859 households accommodated in 13 camps.

Main outcome measures All cause death and number of missing people.

Results 446 deaths and 11 missing people were reported after the 2004 tsunami, of which most (99\%) occurred on the day of the tsunami or within three days thereafter. No deaths were reported for the two and a half month period starting one week after the tsunami.

Conclusions Most mortality after the 2004 tsunami occurred within the first few days of the disaster and was low in the study area.

\section{Introduction}

On 26 December 2004, the most devastating tsunami in recorded history hit the countries around the Indian Ocean. Sri Lanka was the second most affected country, with more than 30000 deaths and half a million people displaced. We carried out a cross sectional household survey in an eastern coastal district of Sri Lanka to describe the distribution of mortality during and after the disaster among internally displaced persons.

\section{Methods}

We carried out our survey from 13 to 18 March 2005. Internally displaced persons were highly mobile, making it difficult to define the sampling framework, thus we included all households in 13 camps in three administrative divisions of Ampara district. After

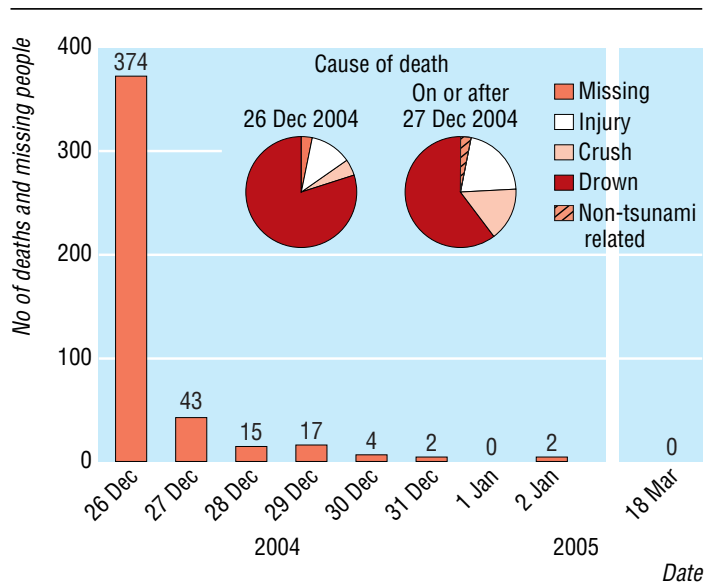

Distribution of 446 deaths and 11 missing people by date among 3533 displaced persons in Ampara district, Sri Lanka on 26 December 2004, day of the tsunami, and subsequent days

written informed consent was obtained, a householder was asked to provide information on all family members as of 25 December 2004 (the day before the tsunami) and any subsequent deaths and missing events. Information on the family was verified by referring to the household registration card, issued by the local government for food rations.

\section{Results}

The study sample consisted of 3533 people from 859 households that gave consent to be surveyed. Of a total of 446 deaths and 11 missing people, most (99\%) occurred on the day of the tsunami or within three days thereafter (figure). No death was observed after 2 January 2005 , the seventh day after the tsunami, indicating low mortality for a displaced population after

This article was posted on bmj.com on 6 January 2006: http://bmj.com/ cgi/doi/10.1136/bmj.38693.465023.7C 
such a massive disaster. Most deaths were due to drowning, followed by tsunami related injury and crush. Only four cases were assumed to be nontsunami related-three due to cardiovascular events and one to injury unrelated to the tsunami.

\section{Discussion}

Mortality related to the Indian Ocean tsunami in 2004 was concentrated in the first few days of the disaster and no death was reported from one week after the tsunami up to two and a half months of the study period. At least six deaths could have been expected among the 3076 survivors and the recall period of 80 days in our study, on the basis of an assumed crude mortality of 0.25 per 10000 person days, a benchmark for displaced populations in South Asia. ${ }^{1}$ The massive additional mortality due to infectious diseases, as warned by the World Health Organization, ${ }^{2}$ was not substantiated.

Our finding can be partly explained by the phenomenon of the "harvesting" effect-that is, decreased mortality after a large number of deaths as a result of an adverse health event among a vulnerable population. This effect has been documented in other disaster settings, such as the earthquake in Taiwan ${ }^{3}$ and the heat waves in the Czech Republic. ${ }^{4}$

The low mortality may also indicate successful aid activities. Prompt international responses were started with sufficient funds. Moreover, the Sri Lankan government functioned sufficiently to coordinate the influx of aid by using its well structured administrative and public health systems.

If this low level of mortality was primarily due to the nature of the disaster, however, then the use of the vast available funds may be questioned. How effective these activities and funds were in relieving the crisis is important in view of, for example, the massive humanitarian crisis that continued at a 10 -fold or higher crude mortality among the displaced population in Darfur, Sudan.

The argument may be circular because the mortality could have been minimised by the extensive relief

\section{What is already known on this topic}

Massive additional mortality among survivors of the 2004 tsunami was a concern, especially due to infectious diseases

\section{What this study adds}

Mortality due to the 2004 tsunami was concentrated in the first few days of the disaster

Increased mortality among displaced persons was not observed

effort of the international community. Nevertheless it can be speculated that the fund raised for the tsunami was disproportionate to need, especially in the context of other ongoing humanitarian crises and global health issues that are continuously costing millions of lives.

Contributors: TA, NN, and OK designed and coordinated the study. TA, DGMC, and SDD carried out and supervised the field study. TA, NN, and KM analysed and interpreted the data. NN wrote the draft and all authors revised the manuscript. NN is the guarantor.

Funding: Grant in aid for special purposes (No 16800056), Ministry of Education, Culture, Sports, Science, and Technology, Japan.

Competing interests: None declared.

Ethical approval: Ethical review committee of the Faculty of Medicine, University of Peradeniya, Sri Lanka.

The Sphere Project. Humanitarian charter and minimum standards in disaster response. Oxford: Oxfam Publishing, 2004.

2 World Health Organization. WHO appeals for US\$ 66 million to prevent disease outbreaks in tsunami-affected Southeast Asia; 150000 people at 'extreme risk' of dying of preventable disease wwwwhoint/mediacentre/ extreme risk of ding of preventable disease. wm

Chan CC, Lin YP, Chen HH, Chang TY, Cheng TJ, Chen LS. A population-based study on the immediate and prolonged effects of the population-based study on the immediate and prolonged effects of

1999 Taiwan earthquake on mortality. Ann Epidemiol 2003;13:502-8.
Kysely J. Mortality and displaced mortality during heat waves in the Kysely J. Mortality and displaced mortality du Czech Republic. Int J Biometeorol 2004;49:91-7.

5 Depoortere E, Checchi F, Broillet F, Gerstl S, Minetti A, Gayraud O, et al. Violence and mortality in West Darfur, Sudan (2003-04): epidemiological evidence from four surveys. Lancet 2004;364:1315-20.

(Accepted 27 October 2005)

doi 10.1136/bmj.38693.465023.7C

\title{
Case reports of suspected adverse drug reactions- systematic literature survey of follow-up
}

\author{
Yoon Kong Loke, Deirdre Price, Sheena Derry, Jeffrey K Aronson
}

\begin{abstract}
Objective To determine whether anecdotal reports of suspected adverse drug reactions are valuable early warning signals.

Design Systematic literature survey.

Data sources We evaluated all case reports of adverse drug reactions published in 1997 in five medical journals. Reports were excluded if the adverse reaction had previously been described in earlier publications and was already listed in the product information of the drug reference source (the British
\end{abstract}

National Formulary (BNF) or the Medicines Compendium). We used the Web of Knowledge Citation Index and Medline for 2003 to identify follow-up studies.

References to the 63 included case reports (w1-w63) and nine validation studies (w64-w72) are on bmj.com.

This is the abridged version of an article that was posted on bmj.38701.399942.63 